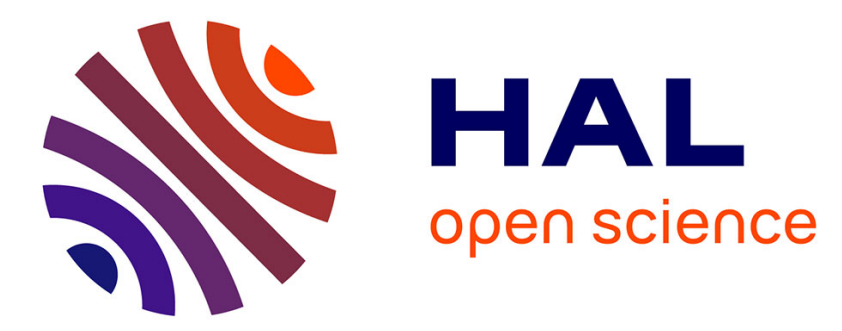

\title{
Room temperature growth of silica nanowires on top of ultrathin Si nanowires synthesized with Sn-Cu bimetallic seeds
}

\author{
Weixi Wang, Éric Ngo, Ileana Florea, Martin Foldyna, Pere Roca I \\ Cabarrocas, Jean-Luc Maurice
}

\section{To cite this version:}

Weixi Wang, Éric Ngo, Ileana Florea, Martin Foldyna, Pere Roca I Cabarrocas, et al.. Room temperature growth of silica nanowires on top of ultrathin Si nanowires synthesized with Sn-Cu bimetallic seeds. physica status solidi (a), 2021, 10.1002/pssa.202100409 . hal-03363508

\author{
HAL Id: hal-03363508 \\ https://hal.science/hal-03363508
}

Submitted on 4 Oct 2021

HAL is a multi-disciplinary open access archive for the deposit and dissemination of scientific research documents, whether they are published or not. The documents may come from teaching and research institutions in France or abroad, or from public or private research centers.
L'archive ouverte pluridisciplinaire HAL, est destinée au dépôt et à la diffusion de documents scientifiques de niveau recherche, publiés ou non, émanant des établissements d'enseignement et de recherche français ou étrangers, des laboratoires publics ou privés. 


\section{Room temperature growth of silica nanowires on top of ultrathin Si nanowires synthesized with $\mathrm{Sn}-\mathrm{Cu}$ bimetallic seeds}

Weixi Wang, Éric Ngo, Ileana Florea, Martin Foldyna*, Pere Roca i Cabarrocas, Jean-Luc Maurice* $^{*}$

Dr. W. Wang 1, Dr. É. Ngo 1, Dr. I. Florea 1, Dr. M. Foldyna 1, Prof. P. Roca i Cabarrocas 1, Dr. J.-L. Maurice 1

LPICM, École polytechnique, CNRS, Institut Polytechnique de Paris, 91120 Palaiseau, France

E-mail: jean-luc.maurice@ polytechnique.edu, martin.foldyna@polytechnique.edu

Keywords: Silicon nanowires, Silica nanowires, Cu-based bi-metallic catalysts, PECVD, TEM

Si nanowires (NWs) are grown by the vapor-liquid-solid method using $\mathrm{Cu}-\mathrm{Sn}$ bimetallic catalysts in a plasma-enhanced chemical vapor deposition (PECVD) reactor. The microstructure of the NWs is analyzed by transmission electron microscopy and energydispersive X-ray spectroscopy. An amorphous $\mathrm{SiO}_{2}$ region, much larger than the native oxide, is present on top of each Si crystalline NW: in SiNWs with diameter below $10 \mathrm{~nm}$, it takes the form of a silica NW of up to $50 \mathrm{~nm}$ in length. The new NW separates the initial catalyst particle into one that stays in contact with the SiNW and one or more that lies at the top of the new NW. The former is made of $\mathrm{Cu}$ and $\mathrm{Cu}_{3} \mathrm{Si}$ and contains no $\mathrm{Sn}$, while the latter keeps amounts of both elements. The observed microstructure appears to be the result of a mechanism of $\mathrm{Si}$ oxidation catalyzed by $\mathrm{Cu}_{3} \mathrm{Si}$. The deposit after $\mathrm{SiNW}$ growth, in the 1 
PECVD reactor, of a protecting 1-nm thick layer of amorphous hydrogenated $\mathrm{Si}$, completely suppresses this mechanism. This work provides reference for future applications based on $\mathrm{Cu}-$ Sn-catalyzed quantum-sized SiNWs.

\section{Introduction}

Developing quantum size Si nanowires (SiNWs) is of interest for different optoelectronic and photovoltaic applications. ${ }^{[1-4]} \mathrm{Si}$ nanowires with a diameter below $10 \mathrm{~nm}$ have a bandgap that increases as their diameter decreases. ${ }^{[5]}$ Interestingly, they can also adopt the metastable hexagonal diamond crystalline structure ${ }^{[6]}$ the calculated electronic structure of which would have specific and interesting opto-electronic properties (increased absorption). ${ }^{[5]}$ In other respects, Si nanowires may be good conductors when properly doped; they can act as efficient collectors for radial junction solar cells ${ }^{[7]}$ for instance.

Obtaining quantum-sized SiNWs with a small diameter distribution has been the object of a number of studies. Some authors have achieved the synthesis of small diameter SiNWs, using well-defined gold nanoclusters as catalysts in a vapor-liquid-solid (VLS) growth process or in a supercritical hexane solution-phase. ${ }^{[3,8-10]}$ However, these methods deliver a small fraction of NWs with sufficiently small diameters. Moreover, the use of gold brings undesirable impurities. In order to consider using large area quantum wire devices, gold-free catalysts are needed. We have achieved to grow very dense quantum wire arrays with average diameter around $6 \mathrm{~nm}$ using a plasma-enhanced chemical vapor deposition (PECVD) method with a novel $\mathrm{Sn}-\mathrm{Cu}$ mixed catalyst and a liquid-assisted vapor-solid-solid (LAVSS) mechanism. ${ }^{[11]}$ This work is the object of a forth-coming paper.

However, these NWs systematically wear an amorphous cap, which can become an actual NW on top of the Si NWs. We show in this paper that this amorphous cap or NW is the result of the oxidation of the $\mathrm{SiNW}$, catalyzed by $\mathrm{Cu}$ in air, as indeed, $\mathrm{Cu}$ is a catalyst of $\mathrm{Si}$ 
oxidation. ${ }^{[12-14]}$ Thus, when the nanowires are taken off from the growth reactor and come into contact with ambient air, the catalyst nanoparticles at their top catalyze the NW oxidation. What makes it particularly interesting is that this oxidation develops at the interface between catalyst and nanowire, where, in nanowires with diameter below $10 \mathrm{~nm}$, it ends up by making - at room temperature in air - a whole Si oxide nanowire.

Silica nanowires, by the way, have been the object of intense efforts these last two decades, due to their wide range of potential applications, from intensive blue-light emitters ${ }^{[15-17]}$ to separator for Li-ion batteries ${ }^{[18]}$ or biosensors. ${ }^{[19]}$ Regarding Si-silica heterostructures, the coupling of silica nanostructures with SiNWs has been demonstrated to strongly enhance or modify the NW luminescence. ${ }^{[20-22]}$

In this paper however, we focus on the characterization of the silica NW and on the way of avoiding its formation. We analyze the NW microstructure by transmission electron microscopy (TEM) and energy-dispersive X-ray spectroscopy (EDX). We manage to suppress the formation of the silica nanowire by coating the SiNWs with an $a$-Si:H thin film in the PECVD reactor.

In the following, we start by showing the structure and chemical composition of silica NWs and of the separated parts of the original catalyst particle; then we discuss the formation of the amorphous oxide NW in between the crystalline SiNW and the remnants of the catalyst, in the light of literature on $\mathrm{Cu}$-catalyzed oxidation of Si wafers.

\section{Results}

\subsection{TEM analysis}

The SiNWs discussed in the following were grown using a mixed catalyst of $0.1 \mathrm{~nm} \mathrm{Sn} / 0.1$ $\mathrm{nm} \mathrm{Cu}(70$ at. \% Cu) with the typical PECVD conditions (see Experimental Section). They have diameters ranging from 4 to $9 \mathrm{~nm}$ with an average diameter of $6.3 \mathrm{~nm}$ (measured by 
TEM based on 89 SiNWs); the average diameter of their crystalline core is around $4 \mathrm{~nm} .^{[11]}$ They have thus the size where the band gap depends on wire diameter. TEM observation shows that these thin SiNWs systematically have a special structure with an amorphous nanowire separating the initial single-particle catalyst into several nanoparticles (NPs). That amorphous NW was present in all the 89 SiNWs observed; its length could vary from 10 to 50 nm: Figure 1a \& b shows typical configurations. The HRTEM image in Figure 1c presents a SiNW in [110] zone axis, where the differences in structure between the crystalline core of the Si NW and its amorphous tip and shell are well visible (see schematic in Figure 1d). There is a catalyst NP (catalyst 1 ) connected to the crystalline core. However, this is not the end of the NW; we can see that there is still an amorphous part with a length around $10 \mathrm{~nm}$ above the crystalline core, on top of which lies catalyst 2 (with one or more catalyst NPs).

Let us add here that the substrate appears to play no role: the amorphous NW was found on SiNWs grown on (100) Si (Figure 1a) or on the amorphous C-membrane of TEM grids (Figure 1b, c), or on the metallic grids themselves. The only limitation we noticed was that of size: the starting particles had to be smaller than $\sim 10 \mathrm{~nm}$ for an actual amorphous wire to develop.

This catalyst separation phenomenon along with the growth of the amorphous NW has only been observed in the SiNWs synthesized with $\mathrm{Sn}-\mathrm{Cu}$ and $\mathrm{In}-\mathrm{Cu}$ mixed catalysts, never in SiNWs synthesized with pure Sn or Au catalyst. ${ }^{[11]}$ (Let us mention that SiNWs cannot be grown with pure $\mathrm{Cu}$ catalysts under the current PECVD conditions. ${ }^{[11]}$ ) 

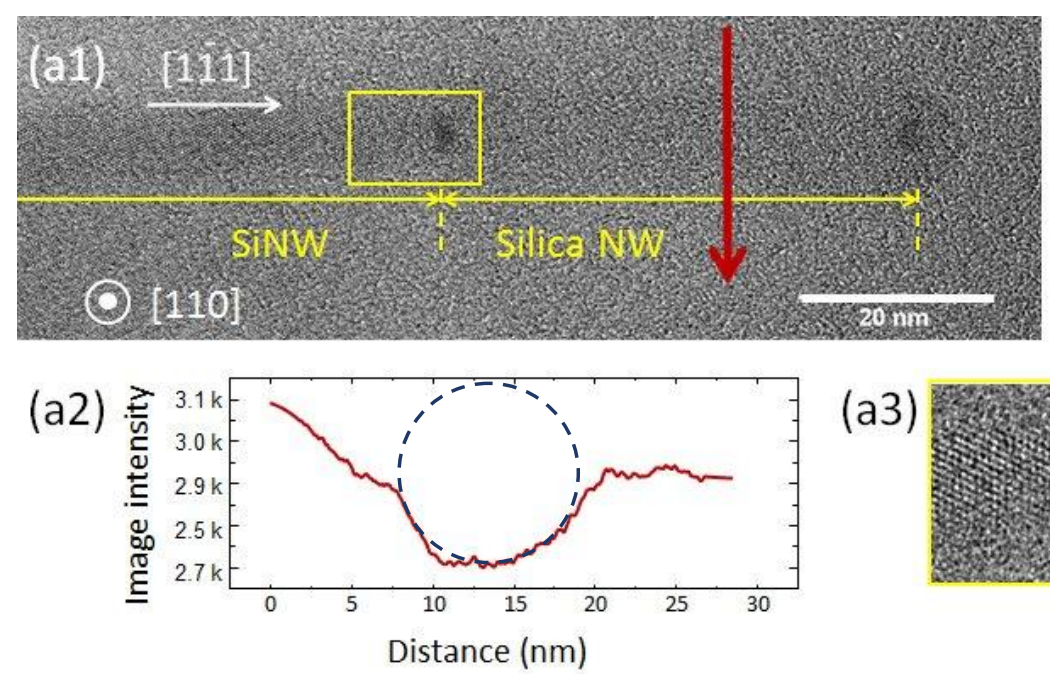

(a3)
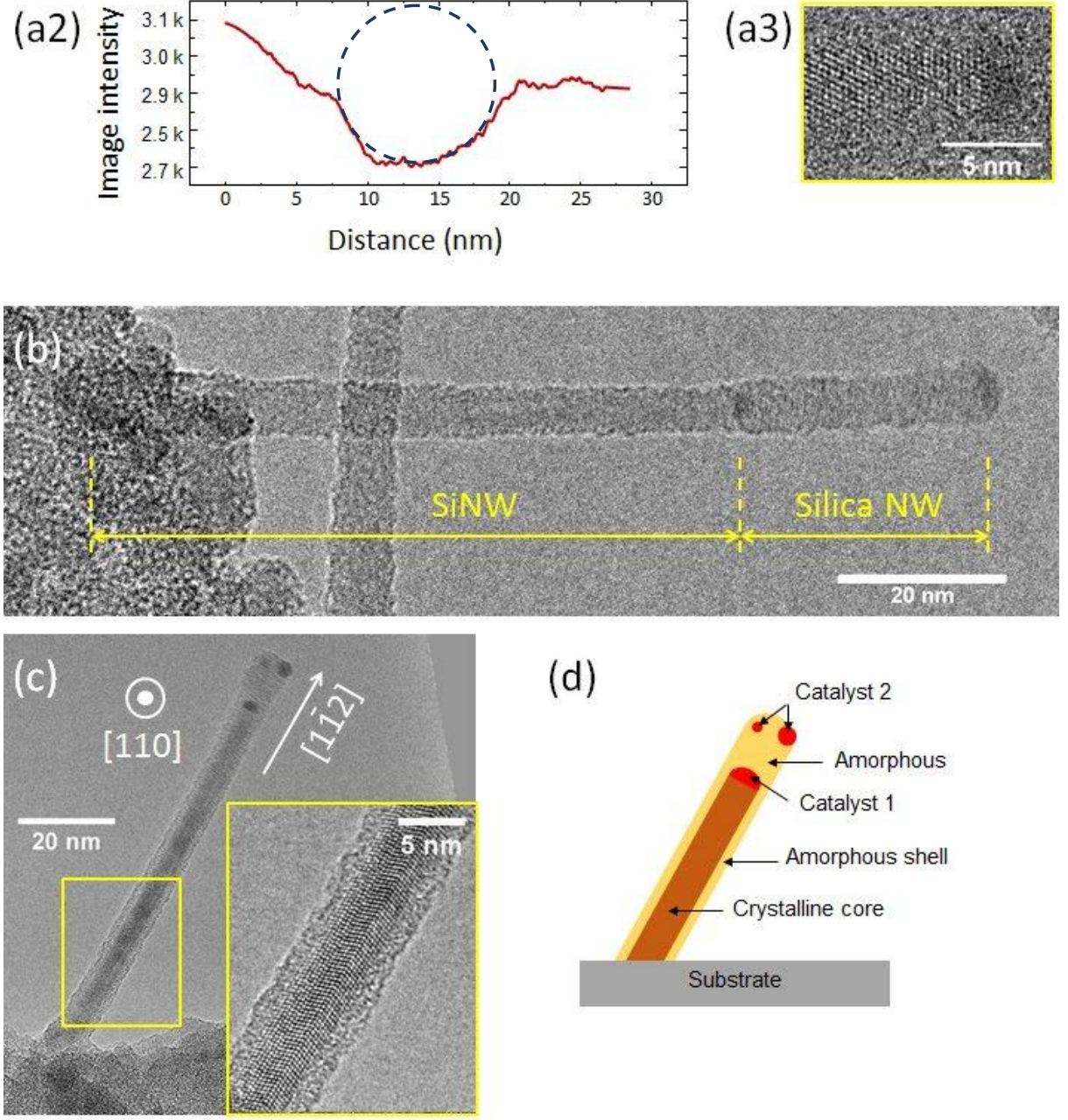

(d)

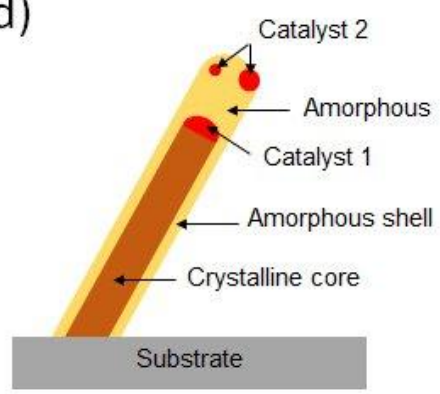

Figure 1. Typical examples of silica NWs grown on top of SiNWs. a) NW synthesized with $0.1 \mathrm{~nm} \mathrm{Sn} / 0.1 \mathrm{~nm} \mathrm{Cu}$ as catalyst on (100) Si then scratched and deposited on the amorphous C-membrane of a TEM grid; TEM close to [110] zone axis of the SiNW, showing its $<111>$ orientation; a2) intensity profile over the red arrow in (a1), integrated over the length of the amorphous NW, showing its presence (dashed circle); a3) enlargement of squared area in (a1) . b) Same catalyst and same recipe with growth directly on the TEM grid amorphous 
membrane (SiNW out of zone axis); same scale as (a1). c) [110] zone axis image of a similar SiNW, showing its $<211>$ orientation; the enlarged area shows the details of the twinned crystalline core. d) Schematic of (c).

\subsection{EDX analysis}

Due to irradiation damage, we were not able to record X-ray maps of the NWs: the objects would become irreversibly damaged before a sufficient signal-to-noise-ratio had developed. Thus, we carried out point analyses, obtained by leaving a non-focused beam a short time on the NWs. In Figure 2, we show an EDX analysis on two separated catalyst NPs as well as on the amorphous part between them, in the case of a thin SiNW grown in the same run with 0.1 $\mathrm{nm} \mathrm{Sn} / 0.1 \mathrm{~nm} \mathrm{Cu}$ bimetallic catalyst. In area 1, the catalyst NP in contact with the crystalline $\mathrm{NW}, \mathrm{O}, \mathrm{Si}$ and $\mathrm{Cu}$ are found. $\mathrm{Cu}$ has a strong signal. No trace of $\mathrm{Sn}$ is found in this catalyst NP. In area 2, the amorphous part, $\mathrm{O}$ and $\mathrm{Si}$ are mainly detected. The atomic ratio of $\mathrm{O}$ and $\mathrm{Si}$ is 9:4, close to the ratio in $\mathrm{SiO}_{2}$. Therefore, it is reasonable to speculate that the part between the two catalyst NPs is $\mathrm{SiO}_{2}$. The signals of $\mathrm{Cu}$ and $\mathrm{Sn}$ in this area are relatively low, just above the background noise. On the top particle of the NW in area 3, the presence of $\mathrm{O}, \mathrm{Si}$, $\mathrm{Cu}$ and $\mathrm{Sn}$ are confirmed. Putting aside the signals from $\mathrm{Si}$ and $\mathrm{O}$, that are influenced by the proximity of the $\mathrm{SiO}_{2}$, one can measure the atomic fractions of $\mathrm{Cu}$ and $\mathrm{Sn}$ in this area. As the $\mathrm{Cu}$ signal is at about twice the noise level, the uncertainty on its value is large. These fractions come at $20 \pm 15 \%$ and $80 \pm 15 \%$ respectively: $\mathrm{Sn}$ is present in contrast to its absence in the other part of the catalyst and, compared to the starting atomic ratio of $70 \%$ the amount of $\mathrm{Cu}$ has drastically decreased. Thus, some $\mathrm{Cu}$ has diffused away from the original catalyst to form a new one at the interface between $c-\mathrm{Si}$ and $a-\mathrm{SiO}_{2}$. 

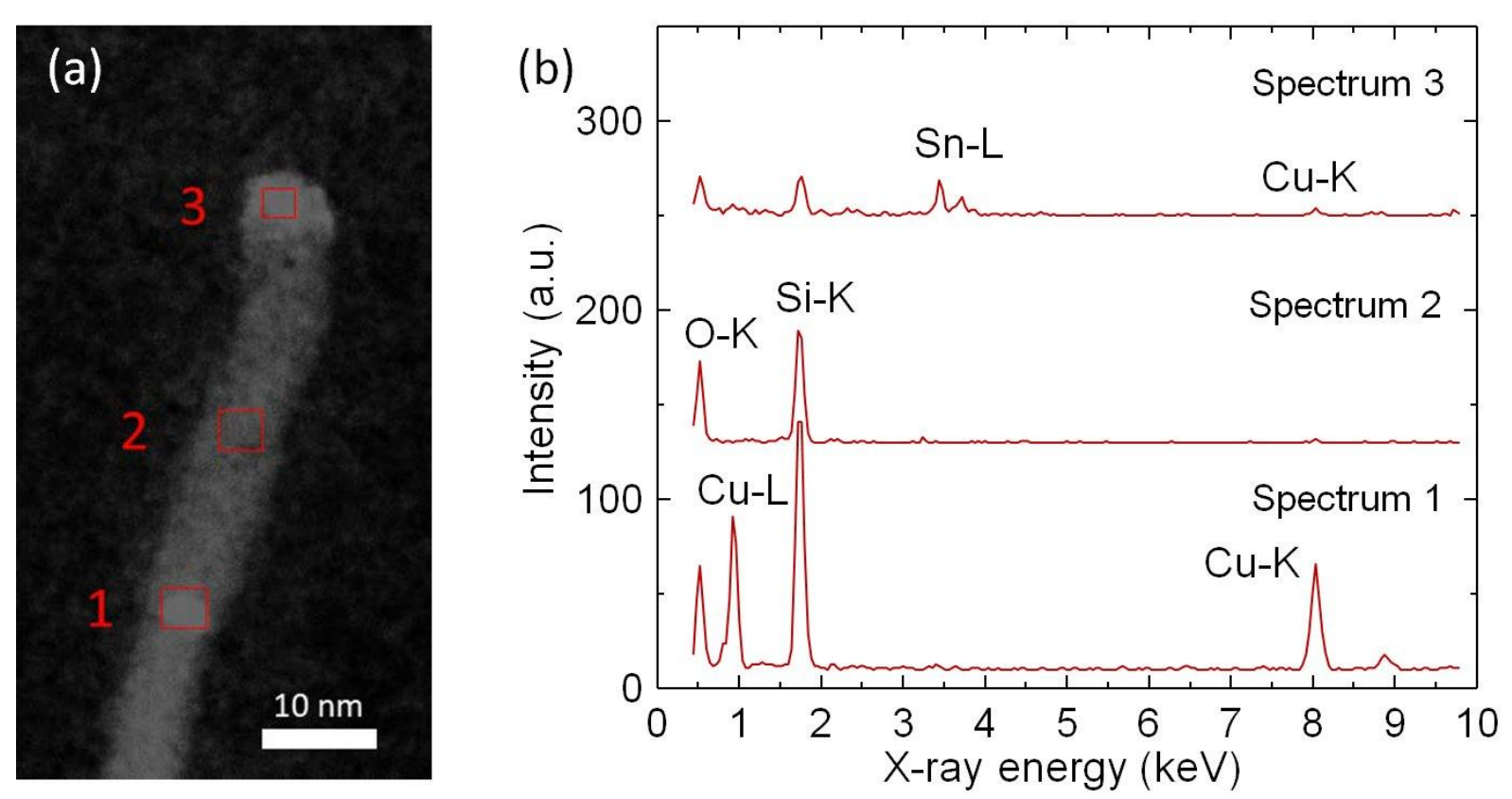

Figure 2. EDX analysis on a silica NW and a split catalyst. (a) STEM-HAADF image; (b) EDX spectra. Area and spectrum 1 correspond to the catalyst part that is connected to the SiNW, area and spectrum 2 to the amorphous part between the two catalyst NPs, and area and spectrum 3 to the top catalyst NP. The SiNW is synthesized with $0.1 \mathrm{~nm} \mathrm{Sn} / 0.1 \mathrm{~nm} \mathrm{Cu}$ cocatalyst at the typical conditions.

\subsection{Eliminating post-growth oxidation}

In order to verify whether the formation of the silica nanowires has occurred during processing in the PECVD reactor chamber, or after NW growth in the atmosphere, we performed the following growth experiment. Immediately after NW growth in exactly the same conditions as those mentioned above, we decreased the substrate temperature to $185{ }^{\circ} \mathrm{C}$, and deposited a thin layer of hydrogenated amorphous $\mathrm{Si}(a-\mathrm{Si}: \mathrm{H})$ on the SiNWs, thus "freezing" the original structure and protecting it from exposure to the air when the chamber was opened. A TEM image of a SiNW with amorphous silicon layer is shown in Figure 3. 
The SiNW has a total diameter of $10 \mathrm{~nm}$ and the shell around the NP has a thickness around 2 $\mathrm{nm}$. At the top of this NW, we only find one catalyst NP and no oxide NW. We have observed the structures of $30 \mathrm{SiNWs}$, and none of them had several catalyst NPs separated by amorphous matter. Therefore, we can conclude that $i$ ) catalyst separation and the growth of the silica NW happen after SiNW growth in the ambient air and ii) the deposit of $a-\mathrm{Si}: \mathrm{H}$ in the PECVD reactor immediately after SiNW growth is an efficient way of suppressing all postgrowth oxidation phenomena.

Thus, for preparing unoxidized quantum-sized SiNWs with such catalysts, the deposit of $a$ $\mathrm{Si}: \mathrm{H}$ in the same reactor appears as a mandatory step. As, moreover, $a$-Si:H is known to electrically passivate crystalline Si surfaces ${ }^{[23]}$, the present protection process, which implies only a light treatment in the same reactor, would be a good solution for future measurements of the optical properties or use in devices. 

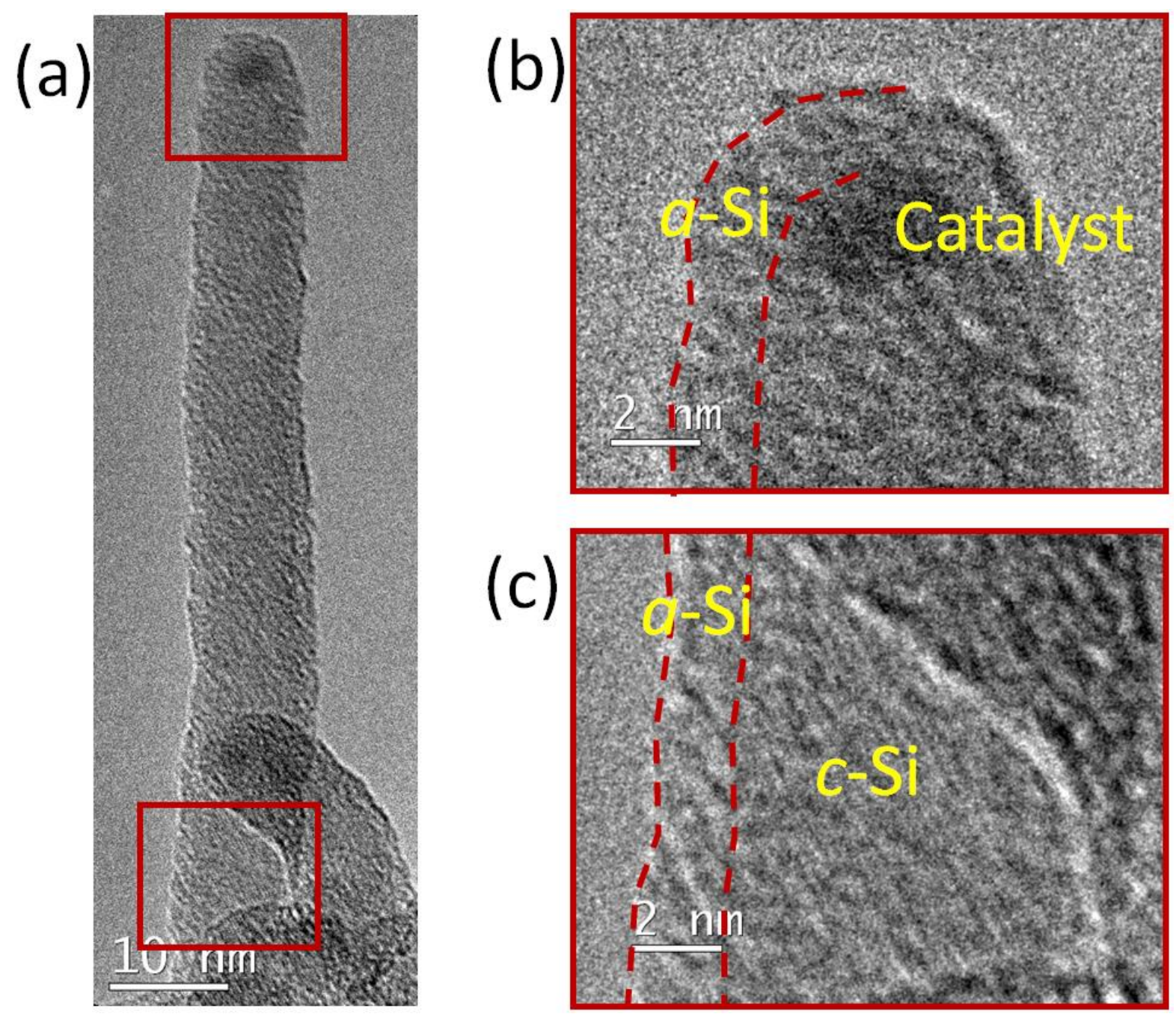

Figure 3. a) TEM image of a SiNW with a thin layer of amorphous Si deposited immediately after NW growth. b) Enlargement of the top squared area in (a) showing the a-Si:H layer around the catalyst. c) Enlargement of the bottom squared area where the lattice fringes are visible, so that crystalline Si can be differentiated from $a$-si:H and the thickness of the deposited $a-\mathrm{Si}: \mathrm{H}$ can be measured directly: its value is $2 \mathrm{~nm}$.

\section{Discussion}

To evaluate the possible formation mechanism of the silicon oxide NWs and the catalyst splitting, let us make a brief review of the literature. Several authors have demonstrated that $\mathrm{Cu}_{3} \mathrm{Si}$ can catalyze the oxidation of crystalline silicon at room temperature, ${ }^{[12-14,24-25]}$ producing $\mathrm{SiO}_{2}$. Harper et al., for example, obtained $\mathrm{Cu}_{3} \mathrm{Si}$ films by sputtering $\mathrm{Cu}$ onto (100) Si at $200{ }^{\circ} \mathrm{C}$. They observed the formation of a thick layer of $\mathrm{SiO}_{2}$ under a copper-rich surface 
after exposure to air at room temperature for a few weeks. They found $\mathrm{Cu}_{3} \mathrm{Si} \mathrm{NPs}$ at the $\mathrm{SiO}_{2} / \mathrm{Si}$ interface. ${ }^{[12]}$ This is similar to what has happened in our SiNWs: $\mathrm{Cu}$ and $\mathrm{Cu}$-silicide nanocrystals have been found in the separated catalyst NPs (see supplementary information, Fig. S1), and between the NPs there is $\mathrm{SiO}_{2}$ according to the TEM characterizations and the EDX analysis. Figure 4 summarizes the reactions that occur in the SiNWs in the air after PECVD growth. We have shown that, during SiNW growth, the mixed Sn-Cu catalyst NPs consist of a crystalline core of $\mathrm{Cu}_{3} \mathrm{Si}$ and a Sn-rich shell. ${ }^{[26]}$ The SiNWs grown with the current PECVD conditions mostly have single crystalline structure (Figure 4a). When the reactor chamber is open and the NWs are exposed to the air, $\mathrm{Cu}_{3} \mathrm{Si}$ in the catalyst first reacts with oxygen to form $\mathrm{SiO}_{2}$ and $\mathrm{Cu}: \mathrm{Cu}_{3} \mathrm{Si}+\mathrm{O}_{2} \rightarrow \mathrm{SiO}_{2}+3 \mathrm{Cu}$. This produces a layer of $\mathrm{SiO}_{2}$ between the catalyst NP and the crystalline SiNW (Figure 4b). Then the Cu atoms released by oxidation of $\mathrm{Cu}_{3} \mathrm{Si}$ diffuse through the $\mathrm{SiO}_{2}$ to the $\mathrm{SiNW}$ (Figure 4c) and give rise to the second reaction: $3 \mathrm{Cu}+\mathrm{Si} \rightarrow \mathrm{Cu}_{3} \mathrm{Si}$ (Figure $4 \mathrm{~d}$ ). The $\mathrm{Cu}$ and $\mathrm{Cu}$-silicide crystals found at the interface with the Si NW have different orientations (see Fig. S1), and the $\mathrm{Cu}_{6} \mathrm{Sn}_{5}$ planes of the top NP are always found perpendicular to the growth direction of the SiNWs (Fig. S1); this shows that the latter are the remnants of the original catalyst, active during growth, while the former have developed afterwards. In addition, no Sn has ever been found in these parts at the interface with the SiNW. Therefore, we think that the Cu silicide nanocrystals connected to the crystalline NW core have formed due to the reaction of $\mathrm{Cu}$ and $\mathrm{Si}$ after the growth. 
(a)

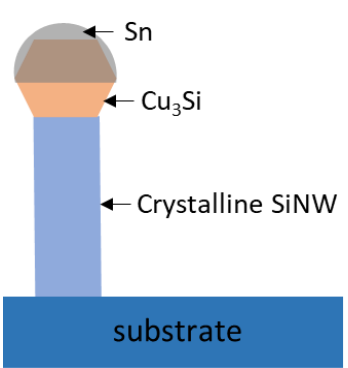

(b)

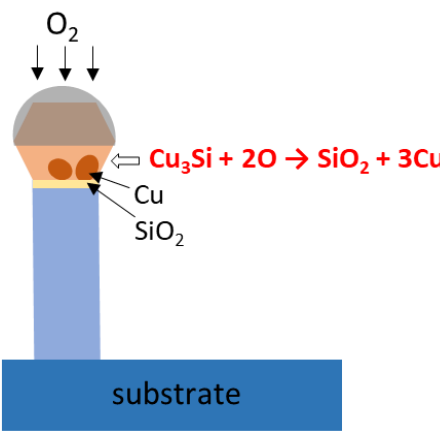

(c)

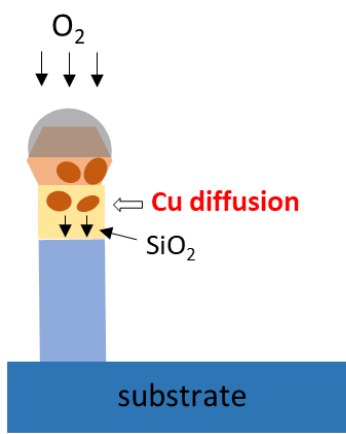

(d)

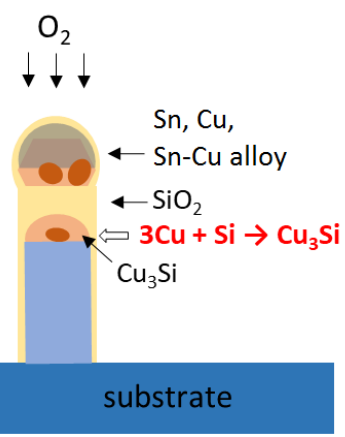

Figure 4. Schematic diagram of formation of a silica $\mathrm{NW}$ catalyzed by $\mathrm{Cu}_{3} \mathrm{Si}$, following the model developed by Harper et al. for the room-temperature oxidation of bulk $\mathrm{Si}^{[12,24]} \mathrm{a}-\mathrm{d}$ ) Time evolution during exposure to air.

However, this reaction sequence does not continue catalytically until the whole SiNW is consumed and has become a $\mathrm{SiO}_{2} \mathrm{NW}$. One may assume that it stops when the $\mathrm{Cu}$ silicide reservoir at the top is exhausted (i.e. when all the Si from the silicide has been oxidized). In other respect, this reaction seems to be limited in thick nanowires (we only found separated catalyst NPs in SiNWs with diameters smaller than $24 \mathrm{~nm}$ ); the explanation could be related to the fact that, to feed the production of $\mathrm{SiO}_{2}$, oxygen from the air must diffuse through the interface between $\mathrm{Cu}_{3} \mathrm{Si}$ and the existing $\mathrm{SiO}_{2}$, down to the center of the wire, over a distance worth a wire radius. That distance would just become too long in thick wires. This is different from the experiments on Si wafers, where oxygen would come from the top; here, after some $\mathrm{Cu}$ has diffused through the oxide, $\mathrm{Sn}$ becomes majority element at the top (see Figure 2) and $\mathrm{Cu}_{6} \mathrm{Sn}_{5}$ replaces the initial $\mathrm{Cu}_{3} \mathrm{Si}$ (see Fig. $\mathrm{S} 1$ ), preventing air oxygen to get in contact directly with $\mathrm{Cu}$ silicide.

\section{Conclusions}


In this work, we have evidenced the growth, at room temperature in air, of silica nanowires on top of thin SiNWs catalyzed by $\mathrm{Sn}-\mathrm{Cu}$ mixed catalysts: the catalyst particle that remains connected to the crystalline NW core is not anymore at the end of the NW, an amorphous silicon oxide has developed above the crystalline core, on top of which lies another one or more catalyst particles. The initial catalyst particle has split into two or more new particles. This appears to be due to the oxidation of the $\mathrm{Cu}$-silicide inside the initial particle in the air after growth: $\mathrm{Cu}_{3} \mathrm{Si}$ first reacts with oxygen to form $\mathrm{SiO}_{2}$ and $\mathrm{Cu}$; then the $\mathrm{Cu}$ atoms released by oxidation of $\mathrm{Cu}_{\mathrm{x}} \mathrm{Si}$ move towards the $\mathrm{SiNW}$ through $\mathrm{SiO}_{2}$ and react with $\mathrm{Si}$ to form new $\mathrm{Cu}_{3} \mathrm{Si}$. It thus adds silica NWs on top of the original SiNWs, which may drastically extend and enhance the luminescence of such objects. ${ }^{[20-22]}$ This, in turn offers new prospects of applications. Inversely, we also showed that the development of the silica NW can be totally inhibited by the deposition, in the same growth reactor, of an $a$-Si:H passivating layer. As the latter, in turn, would also suppress surface recombination of minority carriers, we believe that this treatment could be used in future $\mathrm{Si}$ quantum wires prepared with $\mathrm{Cu}$-based catalysts. This work provides reference for future applications based on $\mathrm{Cu}$-Sn-catalyzed quantum-sized SiNWs.

\section{Experimental section}

We used a mixed catalyst of $\mathrm{Sn}$ and $\mathrm{Cu}$ prepared in a Boc Edwards Auto 306 Evaporator FL 400 to obtain small-diameter SiNWs. Cu was first evaporated on the substrates and then Sn was evaporated on top of $\mathrm{Cu}$ to act as the $\mathrm{Sn}-\mathrm{Cu}$ mixed catalyst. The nominal thickness of the evaporated catalyst was measured by a quartz microbalance in the thermal evaporator. The catalysts were evaporated either on (100) Si wafers or on the amorphous carbon membrane of carbon-coated gold TEM grids for the convenience of TEM observation. SiNWs were synthesized in a radio frequency (RF) PECVD reactor. After the vacuum reached $5 \times 10^{-5}$ 
mbar, a hydrogen plasma treatment was carried out at $200{ }^{\circ} \mathrm{C}$ to remove the native oxide formed around the catalyst NPs before the SiNW growth. During the treatment, the $\mathrm{H}_{2}$ flow rate, the gas pressure $P$, the RF plasma power density and the duration time $t$ were $100 \mathrm{sccm}$, $0.8 \mathrm{mbar}, 57 \mathrm{~mW} \mathrm{~cm}{ }^{-2}$ and $2 \mathrm{~min}$, respectively. Then SiNWs were grown at $416{ }^{\circ} \mathrm{C}$ by adding a $\mathrm{SiH}_{4}$ flow of $5 \mathrm{sccm}$ and changing the process parameters to the following values: $P$ of 1.42 mbar, RF power density of $17 \mathrm{~mW} \mathrm{~cm}^{-2}$ for $t=3 \mathrm{~min}$. After SiNW growth, the substrate temperature was either: $i$ ) decreased to $140{ }^{\circ} \mathrm{C}$, at which point we open the chamber (this set of conditions is referred as the "typical PECVD conditions" in the text); or ii) decreased to $185^{\circ} \mathrm{C}$, at which point an amorphous silicon layer was deposited on the SiNWs and their catalysts, to inhibit oxidation of the latter. The PECVD parameters used in this process were: $10 \mathrm{sccm}$ for $\mathrm{SiH}_{4}$ flux, $0.17 \mathrm{mbar}$ for gas pressure, $1 \mathrm{~W}$ for RF power, and $30 \mathrm{~s}$ for time duration. The chamber was opened after the substrate had cooled down to $140{ }^{\circ} \mathrm{C}$. The purpose of coating the SiNWs with an amorphous silicon layer was to prevent the catalyst and the crystalline NW from oxidation in the air and ascertain the origin of silica NW formation. The SiNWs were characterized by transmission electron microscopy (TEM) for high resolution (HR) imaging and Energy Dispersive X-ray spectroscopy (EDX) analysis using a Jeol 2010F and a Thermo Fisher Titan 80-300. The acceleration voltages utilized were $200 \mathrm{kV}$ for the Jeol 2010F TEM (0.16-nm information limit), and $300 \mathrm{kV}$ for the Titan TEM (0.12-nm information limit), respectively. Some high-angle annular dark-field (HAADF) images were recorded in scanning TEM (STEM) mode, prior to EDX analysis with the Titan. EDX was performed using an INCA system from Oxford Instruments, equipped with a silicon drift detector. The use of Au TEM grids (instead of standard $\mathrm{Cu}$-grids) warranted that the $\mathrm{Cu}$ signal genuinely came from the sample. 
Supporting Information: Supporting Information is available from the Wiley Online Library or from the author: it includes Figure S1: HRTEM structural analysis of split catalyst particle.

\section{Acknowledgements}

This research was funded by the French National Research Agency ANR, through the TEMPOS Equipex, grant number ANR-10-EQPX-50, and the HexaNW project, grant number ANR-17-CE09-0011. Thanks are due to the CIMEX - Centre interdisciplinaire de microscopie électronique de l'X, for the use of the electron microscopes at École polytechnique.

\section{References}

[1] J. Hu, T. W. Odom, C. M. Lieber, Acc. Chem. Res. 1999, 32, 435.

[2] Y. Cui, C. M. Lieber, Science 2001, 291, 851.

[3] R. A. Puglisi, C. Bongiorno, S. Caccamo, E. Fazio, G. Mannino, F. Neri, S. Scalese, D. Spucches, A. La Magna, ACS Omega 2019, 4, 17967.

[4] W. Chen, P. Roca i Cabarrocas, Nanotechnology 2019, 30, 194002.

[5] M. Amato, T. Kaewmaraya, A. Zobelli, M. Palummo, R. Rurali, Nano. Lett. 2016, 16, 5694.

[6] J. Tang, J.-L. Maurice, F. Fossard, I. Florea, W. Chen, E. V. Johnson, M. Foldyna, L. Yu, P. Roca i Cabarrocas, Nanoscale 2017, 9, 8113.

[7] S. Misra, L. Yu, M. Foldyna, P. Roca i Cabarrocas, Sol. Energy Mater. Sol. Cells 2013, 118,90 .

[8] Y. Wu, Y. Cui, L. Huynh, C. J. Barrelet, D. C. Bell, C. M. Lieber, Nano. Lett. 2004, 4, 433.

[9] Y. Cui, L. J. Lauhon, M. S. Gudiksen, J. Wang, C. M. Lieber, Appl. Phys. Lett. 2001, $78,2214$.

[10] J. D. Holmes, K. P. Johnston, R. C. Doty, B. A. Korgel, Science 2000, 287, 1471.

[11] W. Wang, PhD thesis, Institut Polytechnique de Paris, École polytechnique, 01/06/2021, 2021. 
[12] J. M. E. Harper, A. Charai, L. Stolt, F. M. d'Heurle, P. M. Fryer, Appl. Phys. Lett. 1990, 56, 2519.

[13] C. Lampe-Önnerud, U. Jansson, A. Hårsta, J.-O. Carlsson, J. Cryst. Growth 1992, 121, 223.

[14] J. Li, D. Adams, S. W. Russell, T. L. Alford, J. W. Mayer, in Control of Semiconductor Interfaces, DOI: 10.1016/b978-0-444-81889-8.50041-9 (Eds: I. Ohdomari, M. Oshima, A. Hiraki), Elsevier, Amsterdam 1994, p. 217.

[15] D. P. Yu, Q. L. Hang, Y. Ding, H. Z. Zhang, Z. G. Bai, J. J. Wang, Y. H. Zou, W. Qian, G. C. Xiong, S. Q. Feng, Appl. Phys. Lett. 1998, 73, 3076.

[16] L. Z. Cao, H. Song, H. Jiang, H. X. Lu, Y. D. Li, J. Q. Zhao, Journal of Inorganic and Organometallic Polymers and Materials 2011, 21, 823.

[17] Q. Wei, G. Meng, X. An, Y. Hao, L. Zhang, Solid State Communications 2006, 138, 325.

[18] Q.-C. Du, M.-T. Yang, J.-K. Yang, P. Zhang, J.-Q. Qi, L. Bai, Z. Li, J.-Y. Chen, R.-Q. Liu, X.-M. Feng, Z.-D. Huang, T. Masese, Y.-W. Ma, W. Huang, Acs Applied Materials \& Interfaces 2019, 11, 34895.

[19] A. Kaushik, R. Kumar, E. Huey, S. Bhansali, N. Nair, M. Nair, Microchimica Acta 2014, 181, 1759.

[20] Z. L. Wang, Z. R. Dai, R. P. Gao, Z. G. Bai, J. L. Gole, Appl. Phys. Lett. 2000, 77, 3349 .

[21] B. K. Teo, C. P. Li, X. H. Sun, N. B. Wong, S. T. Lee, Inorg. Chem. 2003, 42, 6723.

[22] C. H. Ye, L. D. Zhang, X. S. Fang, Y. H. Wang, P. Yan, J. W. Zhao, Advanced Materials 2004, 16, 1019.

[23] D. Deligiannis, R. Vasudevan, A. H. M. Smets, R. A. C. M. M. v. Swaaij, M. Zeman, AIP Advances 2015, 5, 097165.

[24] L. Stolt, A. Charai, F. M. D’Heurle, P. M. Fryer, J. M. E. Harper, J. Vac. Sci. Technol. A 1991, 9, 1501.

[25] H. Y. Huang, L. J. Chen, J. Appl. Phys. 2000, 88, 1412.

[26] É. Ngo, PhD thesis, Institut Polytechnique de Paris, École polytechnique, 13/04/2021, 2021. 